\title{
Impact of lymphoceles on organ at risk doses in patients undergoing adjuvant pelvic radiation for carcinoma cervix
}

\author{
Chandani Hotwani ${ }^{1}$, Supriya Chopra ${ }^{2}$, Nara Moirangthem², Sarthak Mohanty ${ }^{1}$, \\ Siji N Paul ${ }^{2}$, Reena Engineer ${ }^{1}$, Umesh Mahantshetty ${ }^{1}$, Shyam Kishore Shrivastava ${ }^{1}$ \\ ${ }^{I}$ Department Radiation Oncology and Medical Physics, Tata Memorial Hospital, Tata Memorial Centre, Mumbai, India \\ ${ }^{2}$ Department of Radiation Oncology, Advanced Centre for Treatment Research and Education in Cancer, Tata Memorial Centre, \\ Mumbai, India
}

Received January 30, 2015; Revised April 11, 2015; Accepted April 22, 2015; Published Online May 30, 2015

\section{Original Article}

\begin{abstract}
Purpose: Lymphoceles form part of target volume during adjuvant radiation for cervical cancer. The impact of lymphocele on doses to adjacent organs at risk (OAR) has not been studied. The present study was designed to investigate the same. Methods: From January 2011- December 2013 all patients were evaluated for presence of postoperative lymphocele. Planned target volume (PTV) was generated with and without lymphocele volume. Intensity modulated radiation therapy (IMRT) plans were generated and dose to OARs was determined. The impact of lymphocele volume on OAR dose was determined by Spearman rank test and Wilcoxon sign rank sum test was performed to determine the impact of lymphocele on OAR dose. Results: A total of 11/93 patients had postoperative lymphoceles. Of these $63 \%$ were located in internal iliac region. The median lymphocele volume at simulation was $42.8 \mathrm{cc}$ (range 6.4-105cc) and remained almost stable at $44 \mathrm{cc}$ (range 3-100 cc) at fifth week of radiation. Negative correlation was observed between mean lymphocele volume and dose to bladder, rectum and bowel bag. Presence of lymphocele led to reduction in V30 and V40 of bladder (84 cc vs 77 cc, $p=0.004 ; 68$ cc vs 63 cc; $p=0.01$ ) and rectum ( 87 cc vs 80 cc, $p=0.0001 ; 73.5$ cc vs 65 cc, $p=0.01$ ) and V15 of bowel bag (843 cc vs 804 cc; $p=0.01$ ). Conclusion: Presence of lymphoceles displaced OARs leading to reduction in high dose volumes of rectum and bladder.
\end{abstract}

Keywords: Lymphoceles; IMRT; Cervix

\section{Introduction}

Lymphocele is defined as an extra-peritoneal space which lacks epithelial lining and is filled with lymph. It is a common complication after gynecological oncological surgeries where pelvic lymphadenectomy plays an important role, for staging as well as therapeutic purpose. ${ }^{1}$ The incidence of lymphoceles has been reported to range from $16.4 \%$ to as high as $49 \%$ in various earlier series. However, with the improvement in surgical expertise, it has reduced to less than $6 \%{ }^{2,3}$ Other common surgeries related with higher incidence of lymphoceles include urological surgeries and renal transplantation. Lymphoceles usually appear between 2-8 weeks after surgery and majority of them resolve spontaneously, usually within 6 months after surgery. ${ }^{4}$ The volume of lymphocele is dependent on type of surgery, extent of lymph node dissection, surgeons' skills, etc. ${ }^{5}$ Lymphoceles, if small, are usually asymptomatic and are managed conservatively. The indications for active management include large lymphoceles causing pressure effects, infection or deep vein thrombosis.
Lymphoceles are included in target volume for patients receiving post-operative radiotherapy for cervical carcinoma as recommended by standard RTOG guidelines. ${ }^{6}$ Although, small volume lymphoceles may not change the target volume, larger volume of lymphoceles may require substantial modification of standard contours and may lead to an increase in dose to normal pelvic organs like bladder, rectum, small bowel and sigmoid. However there is no literature to support or reject this hypothesis. The present study was undertaken to evaluate the impact of post-operative lymphoceles on planning target volume (PTV) and adjacent organs at risk (OAR) in cohort of women undergoing adjuvant pelvic radiation.

\section{Methods and Materials}

Radiation planning computerized tomography scans of all patients scheduled to undergo adjuvant chemoradiation from January 2011- December 2013 within the context of on ongoing phase III randomized trial of adjuvant radiation were reviewed to evaluate presence of post-operative lymphocele. ${ }^{7}$ 
Detailed characteristics related to lymphocele like its location, volume and laterality was recorded. Planning target volume (PTV) was delineated according to the standard guidelines for post-operative radiotherapy. ${ }^{6}$ In addition, lymphocele was delineated as clinical target volume (CTV) lymphocele and a margin of $0.5 \mathrm{~cm}$ was generated to obtain PTV lymphocele. Two PTV volumes i.e. with and without including PTV lymphoceles were generated and intensity modulated radiation therapy (IMRT) plans were generated using Helical Tomotherapy. OARs included bladder, rectum, sigmoid, small and large bowel loops. Highest priority was given for PTV coverage. Amongst OARs, highest priority was given to small bowel sparing. To evaluate impact of presence of lymphocele doses to OARs with and without lymphocele were compared using Wilcoxon sign rank sum test and correlation between lymphocele volume and doses to OARs was studied by Spearman's rank test.
All patients underwent adjuvant chemoradiation and vaginal brachytherapy. Adjuvant radiation included $50 \mathrm{~Gy} / 25$ fractions/ 5 weeks with concurrent weekly cisplatin $\left(40 \mathrm{mg} / \mathrm{m}^{2}\right)$ followed by 2 sessions of high dose rate vaginal brachytherapy (6 Gy each delivered a week apart). As we had access to daily images for patients randomized to Tomotherapy arm, the temporal changes in lymphocele volume was recorded on weekly basis. Images were also assessed for any clinically significant reduction or increase in volume that may necessitate adaptive re-planning. For those randomized to conventional arm Computerized Tomography (CT) images obtained at the time of intravaginal brachytherapy were assessed to record pre and post RT changes in lymphocele volume. Follow up CT images were also reviewed for all patients to evaluate temporal changes after completion of chemo-radiation.

TABLE 1: Table depicting indications of treatment, delivered treatment and acute toxicity during treatment.

\begin{tabular}{|c|c|c|c|c|}
\hline Patient & Age(yrs) & Indications of Adjuvant RT & Planned Treatment & Acute Toxicity \\
\hline 1 & 38 & Incomplete Nodal Dissection & $\begin{array}{l}\text { Adjuvant chemoradiation } \\
\text { and vaginal brachytherapy }\end{array}$ & $\begin{array}{l}\text { Grade I GI } \\
\text { Grade I Hematological } \\
\text { Grade I Renal }\end{array}$ \\
\hline 2 & 47 & $\begin{array}{l}\text { Deep stromal information. Inade- } \\
\text { quate pathological information on } \\
\text { vaginal and parametrial cut margins }\end{array}$ & $\begin{array}{l}\text { Adjuvant chemoradiation } \\
\text { and vaginal brachytherapy }\end{array}$ & $\begin{array}{l}\text { Grade II GI } \\
\text { Grade I Hematological } \\
\text { Grade } 0 \text { Renal }\end{array}$ \\
\hline 3 & 52 & $\begin{array}{l}\text { Deep Stromal Invasion, Tumour } \\
\text { extends to vaginal cut margin }\end{array}$ & $\begin{array}{l}\text { Adjuvant chemoradiation } \\
\text { and vaginal brachytherapy }\end{array}$ & $\begin{array}{l}\text { Grade I GI } \\
\text { Grade I Hematological } \\
\text { Grade I Renal }\end{array}$ \\
\hline 4 & 53 & $\begin{array}{l}\text { Parametrial Involvement } \\
\text { Nodal Involvement }\end{array}$ & $\begin{array}{l}\text { Adjuvant chemoradiation } \\
\text { and vaginal brachytherapy }\end{array}$ & $\begin{array}{l}\text { Grade IGI } \\
\text { Grade I Hematological } \\
\text { Grade } 0 \text { Renal }\end{array}$ \\
\hline 5 & 58 & $\begin{array}{l}\text { Deep Stromal Invasion } \\
\text { Lymphovascular space invasion } \\
\text { Nodal Positivity }\end{array}$ & $\begin{array}{l}\text { Adjuvant chemoradiation } \\
\text { and vaginal brachytherapy }\end{array}$ & $\begin{array}{l}\text { Grade II GI } \\
\text { Grade I Hematological } \\
\text { Grade I Renal }\end{array}$ \\
\hline 6 & 43 & $\begin{array}{l}\text { Deep Stromal Invasion. } \\
\text { Inadequate lymph node dissection }\end{array}$ & $\begin{array}{l}\text { Adjuvant chemoradiation } \\
\text { and vaginal brachytherapy }\end{array}$ & $\begin{array}{l}\text { Grade I GI } \\
\text { Grade I Hematological } \\
\text { Grade I Renal }\end{array}$ \\
\hline 7 & 53 & $\begin{array}{l}\text { Deep Stromal Invasion } \\
\text { Lymphovascular space invasion }\end{array}$ & $\begin{array}{l}\text { Adjuvant radiation and } \\
\text { brachytherapy }\end{array}$ & $\begin{array}{l}\text { Grade IGI } \\
\text { Grade I Hematological } \\
\text { Grade } 0 \text { Renal }\end{array}$ \\
\hline 8 & 42 & $\begin{array}{l}\text { Deep Stromal Invasion } \\
\text { Lymphovascular space invasion } \\
\text { Nodal Positivity }\end{array}$ & $\begin{array}{l}\text { Adjuvant chemoradiation } \\
\text { and vaginal brachytherapy }\end{array}$ & $\begin{array}{l}\text { Grade III GI } \\
\text { Grade I Hematological } \\
\text { Grade } 0 \text { Renal }\end{array}$ \\
\hline 9 & 54 & $\begin{array}{l}\text { Deep Stromal Invasion } \\
\text { Vaginal Cut Margin Involvement }\end{array}$ & $\begin{array}{l}\text { Adjuvant chemoradiation } \\
\text { and vaginal brachytherapy }\end{array}$ & Record Not Available \\
\hline 10 & 55 & $\begin{array}{l}\text { Vaginal Cut Margin Positive } \\
\text { Lymph Node Positive }\end{array}$ & $\begin{array}{l}\text { Adjuvant chemoradiation } \\
\text { and vaginal brachytherapy }\end{array}$ & $\begin{array}{l}\text { Grade II GI } \\
\text { Grade I Hematological } \\
\text { Grade I Renal }\end{array}$ \\
\hline 11 & 59 & $\begin{array}{l}\text { Deep Stromal Invasion } \\
\text { Lymphovascular space invasion }\end{array}$ & $\begin{array}{l}\text { Adjuvant radiation and } \\
\text { brachytherapy }\end{array}$ & $\begin{array}{l}\text { Grade II GI } \\
\text { Grade I Hematological } \\
\text { Grade } 0 \text { Renal }\end{array}$ \\
\hline
\end{tabular}


TABLE 2: Characteristics of target volumes and organs at risk.

\begin{tabular}{|c|c|}
\hline Number of Patients & 11 \\
\hline \multicolumn{2}{|l|}{ Location of lymphocele } \\
\hline PreSacral & $02(18.2 \%)$ \\
\hline External Iliac & $02(18.2 \%)$ \\
\hline Internal Iliac & $07(63.6 \%)$ \\
\hline \multicolumn{2}{|l|}{ Laterality } \\
\hline Central & $02(18.2 \%)$ \\
\hline Unilateral & $05(45.4 \%)$ \\
\hline Bilateral & $04(36.4 \%)$ \\
\hline \multicolumn{2}{|l|}{ CTV lymphocele volume } \\
\hline Mean/Median(cc) & $42.8 / 21.6$ \\
\hline Range(cc) & 03.4-107.2 \\
\hline \multicolumn{2}{|l|}{ PTV lymphocele volume } \\
\hline Mean/Median(cc) & $89.8 / 61.0$ \\
\hline Range(cc) & $13.0-210.4$ \\
\hline \multicolumn{2}{|l|}{ PTV primary volume } \\
\hline Mean/Median(cc) & $300.5 / 273.8$ \\
\hline Range(cc) & $194.8-407.3$ \\
\hline \multicolumn{2}{|l|}{ PTV nodal volume } \\
\hline Mean/Median(cc) & $598.5 / 632.6$ \\
\hline Range(cc) & $186.7 / 787.6$ \\
\hline \multicolumn{2}{|l|}{ PTV pelvis with lymphocele volume } \\
\hline Mean/Median(cc) & $843.8 / 876.8$ \\
\hline Range(cc) & $386.7-1069.0$ \\
\hline \multicolumn{2}{|l|}{ PTV pelvis without lymphocele } \\
\hline Mean/Median(cc) & $818.9 / 870.1$ \\
\hline Range(cc) & $375.9-1006.8$ \\
\hline \multicolumn{2}{|l|}{ Bladder volume } \\
\hline Mean/Median(cc) & $272.8 / 260.0$ \\
\hline Range(cc) & $110.8-451.2$ \\
\hline \multicolumn{2}{|l|}{ Rectum volume } \\
\hline Mean/Median(cc) & $48.2 / 48.4$ \\
\hline Range(cc) & $17.1-90.1$ \\
\hline \multicolumn{2}{|l|}{ Small bowel } \\
\hline Mean/Median(cc) & $331.3 / 336.8$ \\
\hline Range(cc) & $47.0-717.6$ \\
\hline \multicolumn{2}{|l|}{ Large bowel } \\
\hline Mean/Median(cc) & $193.1 / 183.4$ \\
\hline Range(cc) & $67.5-371.4$ \\
\hline \multicolumn{2}{|l|}{ Sigmoid colon } \\
\hline Mean/Median(cc) & $53.9 / 54.0$ \\
\hline Range(cc) & $13.2-132.8$ \\
\hline
\end{tabular}

\section{Results}

Overall 11/93 (11.8\%) patients had pelvic lymphoceles at the time of referral for adjuvant radiation. The median time from surgery in this cohort was 2 months (range 2-4 months). The baseline reasons for indications of adjuvant radiation, treatment received and acute toxicities on treatment are listed in Table 1. The presence of lymphocele did not lead to any symptoms. One patient had large volume of pelvic lymphocele (patient 5) at presentation, however as it was not symptomatic, hence no intervention was offered. The most common location of lymphocele was near the internal iliac vessels and was observed in $63 \%$ patients. The location, volume and laterality of lymphoceles and PTV volumes with and without lymphoceles is depicted in Table 2. The temporal changes in lymphocele volumes was available in 9/11 pa- tients. While weekly volumes were available for patients treated with Tomotherapy, week 1 and week 5 volumes were available in 6 patients those treated with conventional radiation. The median lymphocele volume at the time of radiation planning was $42.8 \mathrm{cc}$ (range 6.4-105cc) and remained almost stable at $44 \mathrm{cc}$ (range 3-100 cc) in the fifth week of radiation. Only one patient had significant increase in the volume of lymphocele from $90 \mathrm{cc}$ at the time of planning to $105 \mathrm{cc}$ at first week MVCT scan, which required adaptive replanning (Table 3). However over the course of treatment the lymphocele volume remained stable and was $90 \mathrm{cc}$ in the last week of radiation. 
TABLE 3: Characteristics of lymphocele and temporal variation over course of radiation.

\begin{tabular}{|c|c|c|c|c|c|c|c|c|}
\hline No & $\begin{array}{l}\text { Location of } \\
\text { lymphocele }\end{array}$ & Laterality & $\begin{array}{l}\text { Volume } \\
\text { Simulation }\end{array}$ & $\begin{array}{l}\text { Volume at } \\
1^{\text {st }} \text { week }\end{array}$ & $\begin{array}{l}\text { Volume at } \\
2^{\text {nd }} \text { week }\end{array}$ & $\begin{array}{l}\text { Volume at } \\
3^{\text {rd }} \text { week }\end{array}$ & $\begin{array}{l}\text { Volume at } \\
4^{\text {th }} \text { week }\end{array}$ & $\begin{array}{l}\text { Volume at } \\
5^{\text {th }} \text { week }\end{array}$ \\
\hline 1 & Presacral & Midline & 103.30 & 91.00 & 87.00 & 80.00 & 70.70 & 67.00 \\
\hline 2 & $\begin{array}{l}\text { External } \\
\text { Iliac }\end{array}$ & Unilateral & 07.60 & $\mathrm{~N} / \mathrm{A}^{*}$ & N/A* & $\mathrm{N} / \mathrm{A}^{*}$ & $\mathrm{~N} / \mathrm{A}^{*}$ & 07.50 \\
\hline 3 & $\begin{array}{l}\text { Internal } \\
\text { Iliac }\end{array}$ & Unilateral & 03.43 & 06.40 & 03.88 & 03.61 & 03.44 & 03.00 \\
\hline 4 & $\begin{array}{l}\text { Internal } \\
\text { Iliac }\end{array}$ & Bilateral & 107.17 & N/A* & N/A* & $\mathrm{N} / \mathrm{A}^{*}$ & $\mathrm{~N} / \mathrm{A}^{*}$ & 100 \\
\hline 5 & $\begin{array}{l}\text { Internal } \\
\text { Iliac }\end{array}$ & Bilateral & 90.33 & 105.00 & N/A* & $\mathrm{N} / \mathrm{A}^{*}$ & N/A* & 90 \\
\hline 6 & Presacral & Midline & 77.22 & N/A* & N/A* & $\mathrm{N} / \mathrm{A}^{*}$ & $\mathrm{~N} / \mathrm{A}^{*}$ & 89.00 \\
\hline 7 & $\begin{array}{l}\text { Internal } \\
\text { Iliac }\end{array}$ & Unilateral & 05.96 & 24.00 & 23.80 & $\mathrm{~N} / \mathrm{A}^{*}$ & 20.70 & 17.67 \\
\hline 8 & $\begin{array}{l}\text { External } \\
\text { Iliac }\end{array}$ & Bilateral & 14.66 & N/A* & N/A* & N/A* & N/A* & N/A* \\
\hline 9 & $\begin{array}{l}\text { Internal } \\
\text { Iliac }\end{array}$ & Unilateral & 29.08 & N/A* & N/A* & N/A* & N/A* & N/A* \\
\hline 10 & $\begin{array}{l}\text { Internal } \\
\text { Iliac }\end{array}$ & Unilateral & 11.24 & N/A* & N/A* & N/A* & N/A* & 09.50 \\
\hline 11 & $\begin{array}{l}\text { Internal } \\
\text { Illiac }\end{array}$ & Bilateral & 21.63 & 27.00 & 24.80 & 22.00 & 19.10 & 19.10 \\
\hline
\end{tabular}

${ }^{*}$ Not available: Lymphocele volumes were not available for patients treated with conventional techniques and 2 patients treated with Tomotherapy.

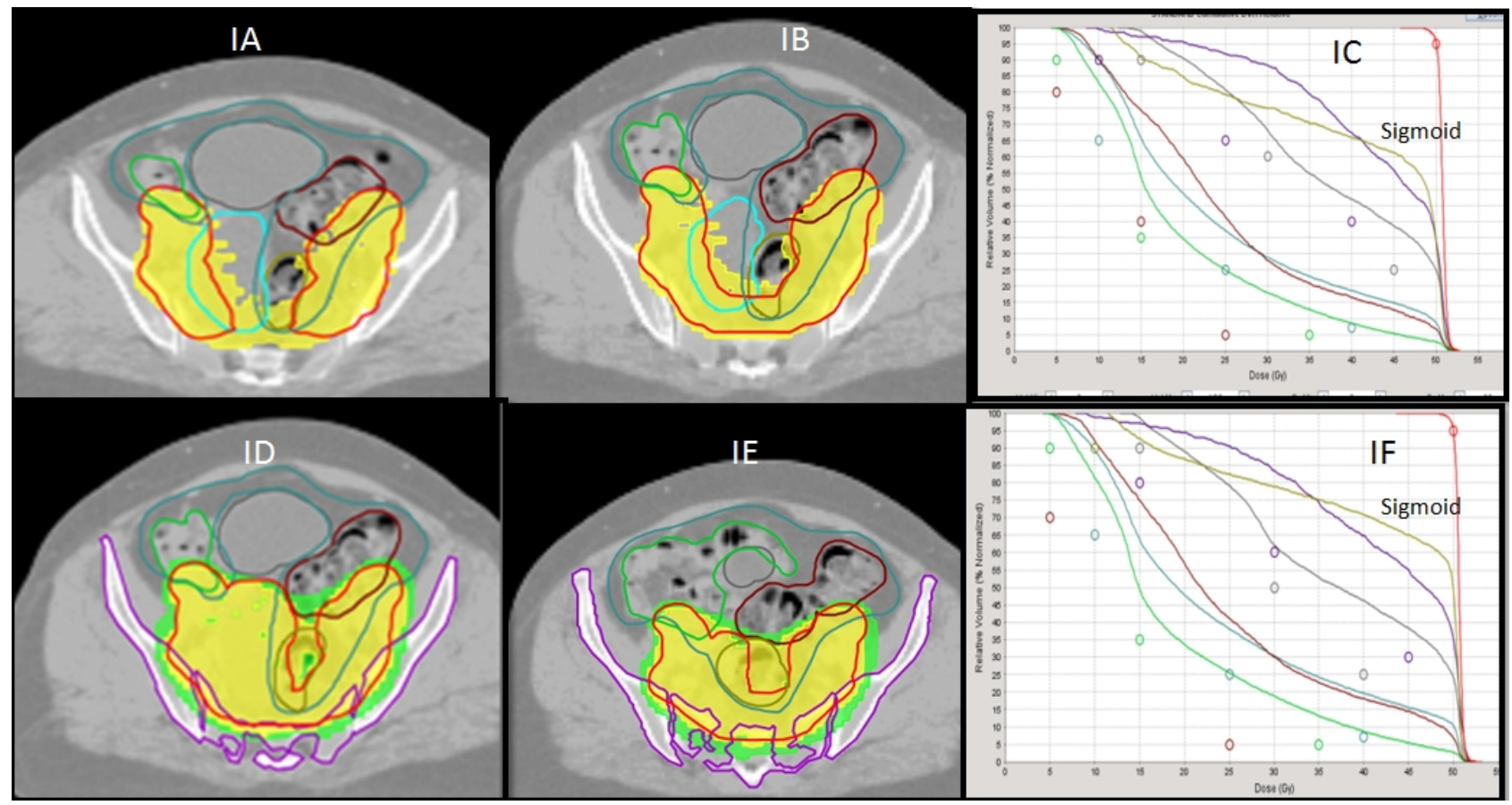

FIG. 1: Figure depicting dose distribution dose volume histogram with and without lymphocele. Figure 1A-C demonstrate dose wash and DVH for planned target volume without lymphocele (lymphocele delineated in light blue). Figure 1D-F demonstrate dose wash and DVH for planned target volume modified to include lymphocele. While most of the OAR's were not impacted in this particular case including lymphocele increased the sigmoid doses

The PTV and OAR doses with and without lymphocele volume is depicted in Table 4 While small volume lymphoceles did not lead to a statistically significant increase in OAR dose, The presence of large lymphoceles reduced the OAR doses by pushing OARs like bladder and bowel outside the true pelvis. Specifically we observed a reduction in volume of bladder and rectum receiving 30 and $40 \mathrm{~Gy}$. While no reduction was observed in small bowel doses we observed reduction in V15 Gy for large bowel and bowel bag. As most of the patients had lymphoceles corresponding to internal 
iliac lymph node region we could not specifically evaluate the impact of location of lymphocele on OAR dose. On correlation between lymphocele volumes with doses to OARs, there was negative correlation between mean lymphocele volume and dose to bladder, rectum and bowel bag, which was not seen for sigmoid colon, small and large bowel when analyzed separately (Table 5). A sample isodose wash and dose volume histogram with and without lymphocele is depicted in Figure 1.

TABLE 4: Impact of Lymphocele Inclusion in PTV on dose received by OARs.

\begin{tabular}{rr|ccc}
\hline \hline Organ \& Dose & $\begin{array}{l}\text { Mean volume } \\
\text { with lymphocele }\end{array}$ & $\begin{array}{l}\text { Mean volume } \\
\text { without lymphocele }\end{array}$ & $p$-value \\
\hline Bladder (\%) & V30 & 77.2 & 84.0 & \\
& V40 & 63.0 & 68.4 & 0.004 \\
V50 & 40.6 & 41.2 & 0.018 \\
Rectum (\%) & & & & \\
& V30 & 80.5 & 87.0 & 0.001 \\
V40 & 65.8 & 73.5 & 0.014 \\
V50 & 33.7 & 38.0 & 0.172 \\
Sigmoid Colon (\%) & & & \\
V30 & 89.6 & 90.1 & 0.522 \\
V40 & 79.2 & 81.3 & 0.215 \\
V50 & 38.9 & 36.7 & 0.461 \\
Small Bowel (cc) & & & \\
V15 & 157.0 & 164.0 & 0.157 \\
V30 & 73.8 & 73.3 & 0.789 \\
V40 & 33.5 & 30.8 & 0.654 \\
V15 & 123.0 & & \\
V30 & 56.5 & 137.0 & 0.069 \\
V40 & 33.5 & 61.5 & 0.421 \\
Large Bowel (cc) & & 30.8 & 0.654 \\
V15 & 804.0 & & 0.013 \\
V30 & 353.0 & 365.0 & 0.095 \\
V40 & 239.0 & 262.0 & 0.203 \\
\hline \hline
\end{tabular}

TABLE 5: Impact Correlation between volume of lymphocele and reduction in dose to normal pelvic structures.

\begin{tabular}{ccc}
\hline \hline Organ & $\begin{array}{c}\text { Mean volume } \\
\text { lymphocele }\end{array}$ & $p$-value \\
\hline Bladder & & \\
V30 & -0.289 & 0.389 \\
V40 & -0.559 & 0.074 \\
V50 & 0.110 & 0.770 \\
Rectum & & \\
V30 & -0.289 & 0.389 \\
V40 & -0.430 & 0.186 \\
V50 & 0.110 & 0.770 \\
Sigmoid colon & & \\
V30 & 0.600 & 0.067 \\
V40 & 0.480 & 0.242 \\
V50 & 0.600 & 0.067 \\
Small bowel & & \\
V15 & 0.267 & 0.428 \\
V30 & -0.069 & 0.840 \\
V40 & 0.149 & 0.662 \\
Large bowel & & \\
V15 & 0.267 & 0.428 \\
V30 & 0.267 & 0.428 \\
V40 & -0.100 & 0.770 \\
Bowel bag & & \\
V15 & 0.500 & 0.141 \\
V30 & 0.000 & 1.000 \\
V40 & -0.100 & 0.798 \\
\hline \hline
\end{tabular}


On follow up imaging, all but one patient had resolution of lymphocele, with a median time to resolution being 6.5 months (range 4-11). In a patient with persistent lymphocele at 12 months post-surgery, lower limb oedema and pain was observed due to pressure effect and pigtail drainage had to be performed for symptomatic relief. Cytological there was no evidence of malignancy in the persistent lymphocele.

\section{Discussion}

Lymphoceles are one of the commonest complication after pelvic surgeries for gynecological malignancies, ranging from 16.4-49 \%.2 The incidence of lymphocele depends on various factors like extent of lymph nodal dissection, use of peri-operative prophylaxis with low molecular weight heparin, approach used for lymphadenectomy, etc. ${ }^{8}$ Tam et al. studied the incidence and natural course of lymphoceles after gynaecological oncological surgeries with serial pelvic ultrasound studies at 2 weeks, 6 weeks, 3, 6, 9 and 12 months post-operatively. ${ }^{4}$ He reported that around $80 \%$ lymphoceles were detected as early as 2 weeks and $96 \%$ by 6 weeks post-surgery. Most of the early detected lymphoceles also resolved spontaneously within 6 months of surgery. Whenever indicated, management includes needle aspiration, percutaneous drainage with or without sclerosis, external drainage or internal drainage with peritoneal marsupialization. ${ }^{9}$

It has been hypothesized that receiving post-operative radiotherapy may interfere with regenerative process of lymphatic endothelium and thus enhance its incidence. But a direct relationship between radiation therapy and incidence of lymphoceles has not been proven. ${ }^{10} \mathrm{We}$ did not observe any new lymphoceles in follow up imaging of the entire cohort (93 patients) included in this study. Volume of lymphocele at the time of simulation and course of radiation is important as it forms a part of target volume for adjuvant radiotherapy. ${ }^{6}$ It may increase the target volume, thus affecting the dose received by normal pelvic organs, especially while treating with conformal techniques. Also, it is important to know the change in volume of lymphocele over a period of time, as changes in volume may necessitate change in target volume, while treating patients using conformal radiotherapy techniques like IMRT. Tam et al. has studied the natural course of pelvic lymhoceles using serial ultrasonography scans for patients undergoing pelvic surgery and reported temporal reduction in the median volume of cysts from $11.1 \mathrm{ml}$ at 2 weeks post-surgery to $6.4 \mathrm{ml}$ at 6 weeks post-surgery. ${ }^{4}$ However limited information is available regarding changes in volume between week 6-14 when patients would be referred for adjuvant radiation. In the present study wherein we had daily MVCT at least for half of the patients we observed minimal change in lymphocele volume over 5 week course of radiation suggesting that re-planning may not really be required for a vast majority of patients.

As far as OAR doses are concerned we observed reduction in V30 and V40 Gy volumes for bladder and rectum and V15 for bowel bag and large bowel doses, on the inclusion of lymphocele into the PTV. Furthermore we observed inverse relationship between lymphocele volume and rectum and bladder dose. As most of the lymphoceles were located in internal iliac region the dosimetric advantage as far as OARs are concerned could be attributed to displacement of OARs outside the high dose region secondary to pressure effect of the lymphocele. While we could not evaluate impact of lymphocele location and OAR doses it is likely that different lymphocele locations may have a different impact. For example a lymphocele at anterolateral external iliac group could possibly end up increasing bladder and bowel doses and a lymphocele at common iliac region could possibly expand target volume increasing bowel doses.

There is lack of strong literature reporting incidence of recurrence in the lymphoceles. Lymphoceles presenting after 1 year post surgery or persisting for a longer duration should create a suspicion for recurrence. Cantrell et al. reported two cases of recurrent squamous cell carcinoma of uterine cervix, where he has suggested any lymphocele appearing six months post-operatively has increased likelihood of harboring recurrent disease and adequate excision of lymphocele for histo-pathological evaluation is the treatment of choice. ${ }^{11}$ In our study we did not observe any new lymphoceles on follow up imaging of 93 patients during the study period. Only one patient had persistent lymphocele however was cytologically negative for recurrence.

\section{Conclusion}

Post-operative lymphoceles are common in the internal iliac nodal group. In the present study we did not observe any appreciable change in lymphocele volume during course of radiation. Inclusion of lymphocele in the target volume often led to reduction in bladder and rectum dose. Impact of lymphocele location however could not be investigated in the present study and remains a subject of future research.

\section{Conflict of interest}

The authors declare that they have no conflicts of interest. The authors alone are responsible for the content and writing of the paper.

\section{References}

1. Kim HY, Kim JW, Kim SH, et al. An analysis of the risk factors and management of lymphocele after pelvic lymphadenectomy in patients with gyneco- 
logic malignancies. Cancer Res Treat 2004; 36:377-83.

2. Mori N. Clinical and experimental studies on the so-called lymphocyst which develops after radical hysterectomy in cancer of the uterine cervix. JJpn Obstet Gynecol Soc 1955; 2:178-203.

3. Gray MJ, Plentl AA, Taylor HC Jr. The lymphocyst: a complication of pelvic lymph node dissections. Am J Obstet Gynecol 1958; 75:1059-62.

4. Tam KF, Lam KW, Chan KK, Ngan HY. Natural history of pelvic lymphocysts as observed by ultrasonography after bilateral pelvic lymphadenectomy. Ultrasound Obstet Gynecol 2008; 32:87-90.

5. Metcalf KS, Peel KR. Lymphocele. Ann R Coll Surg Engl 1993; 75:387-92.

6. Small W Jr, Mell LK, Anderson P, et al. Consensus guidelines for delineation of clinical target volume for intensity-modulated pelvic radiotherapy in postoperative treatment of endometrial and cervical cancer. Int J Radiat Oncol Biol Phys 2008; 71:428-34.
7. Chopra S, Engineer R, Mahantshetty U, et al. Protocol for a phase III randomised trial of image-guided intensity modulated radiotherapy (IG-IMRT) and conventional radiotherapy for late small bowel toxicity reduction after postoperative adjuvant radiation in Ca cervix. BMJ Open 2012; 2pii: e001896.

8. Rutledge F, Dodd GD Jr, Kasilag FB Jr. Lymphocysts; a complication of radical pelvic surgery. Am J Obstet Gynecol 1959; 77:1165-75.

9. Conte M, Panici PB, Guariglia L, et al. Pelvic lymphocele following radical para-aortic and pelvic lymphadenectomy for cervical carcinoma: incidence rate and percutaneous management. Obstet Gynecol 1990; 76:268-71.

10. Dodd GD, Rutledge F, Wallace S. Postoperative pelvic lymphocysts. Am J Roentgenol Radium Ther Nucl Med 1970; 108:312-23.

11. Cantrell CJ, Wilkinson EJ. Recurrent squamous cell carcinoma of the cervix within pelvic-abdominal lymphocysts. Obstet Gynecol 1983; 62:530-4. 